\title{
Proposições não técnicas para uma acessibilidade estética em museus: Uma prática de acolhimento e cuidado
}

\section{Non-technical propositions for an aesthetic accessibility in museums: A welfare and care practice}

\section{Proposiciones no tecnicas para una accesibilidad estética en museos: Una práctica de acogida y cuidado}

\author{
Camila Araújo Alves* \\ Universidade Federal Fluminense - UFF, Niterói, Rio de Janeiro, Brasil \\ Marcia Moraes** \\ Universidade Federal Fluminense - UFF, Niterói, Rio de Janeiro, Brasil
}

\begin{abstract}
RESUMO
Esse artigo tem como objetivo apresentar a mediação como uma via de acesso para a promoção de acessbilidade estética em espaços culturais e museus. Fudamentado na perspectiva feminista da deficiência, o artigo defende que os corpos deficientes interpelam os dispositivos de acessibilidade que são feitos para as pessoas com deficiência, através das prescrições dos manuais técnicos de acessibilidade. Lançando mão de um investimento metodológico que consiste em fazer a acessibilidade COM as pessoas com deficiência, o artigo indica que a acessibilidade é também uma prática de cuidado e acolhimento cuja finalidade é, em última instância, promover uma acessibilildade estética da obra de arte, pela via da experimentação e do encontro.
\end{abstract}

Palavras-chave: mediação, acessibilidade estética, pesquisarCOM.

\begin{abstract}
This article aims to present mediation as a way of an aesthetic accessibility in cultural spaces and museums. Based on feminist perspective of disability, the article argues that disabled bodies interpellate the accessibility devices that are made for people with disabilities, through the prescriptions of accessibility technical manuals. Making use of a methodological investment that consists of making accessibility WITH people with disabilities, the article indicates that accessibility is also a care and welcoming practice whose purpose is, ultimately, to promote an aesthetic accessibility of the work of art, by means of experience and encounter.

Keywords: mediation, aesthetic accessibility, researchWITH.

\section{RESUMEN}

Este artículo tiene como objetivo presentar la mediación como una vía de acceso para la promoción de accesibilidad estética en espacios culturales y
\end{abstract}


museos. Basado en la perspectiva feminista de la discapacidad, el artículo defiende que los cuerpos discapacitados interpelan los dispositivos de accesibilidad que se hacen para las personas con discapacidad, a través de las prescripciones de los manuales técnicos de accesibilidad. El artículo indica que la accesibilidad es también una práctica de cuidado y acogida cuya finalidad es, en última instancia, promover una accesibilidad estética de la obra de arte, por la utilización de una inversión metodológica que consiste en hacer la accesibilidad CON las personas con discapacidad, a través de la experimentación y del encuentro.

Palabras-clave: mediación, accesibilidad estética, pesquisarCON.

E se uma pessoa cega compuser o público visitante em um espaço cultural ou um museu? O que fazer para que essa pessoa acesse as obras expostas, quando muitas delas, senão todas, são obras para serem vistas? O que temos a dizer sobre acessibilidade estética (Alves, 2016), isto é, sobre as possibilidades de fruição de uma obra de arte a partir daquilo que uma pessoa tem, seu corpo, com suas marcas e singularidades?

Começamos a escrita desse texto com as inquietações que nos acossaram e acossam desde que uma de nós, cega, tornou-se educadora e mediadora em um espaço cultural, sendo uma das responsáveis pela elaboração e condução das ações de acessibilidade que ali se realizavam. A inquietação vivida na carne fez nascer uma pesquisa de mestrado (Alves, 2016) orientada pela segunda autora destas linhas. Como já dissemos em outra ocasição (Alves \& Moraes, 2018), nosso encontro se fez no espaço acadêmico, quando uma era aluna de graduação e outra, docente. Foi um encontro entre temporalidades distintas de vida, marcas distintas de corpos e de histórias. Os trabalhos que realizamos em parceria são efeitos também das composições entre tais marcas, cujas tramas vão se tecendo nas pistas de Haraway (1995) ao afirmar que o conhecimento é prática local e situada, que se define pelas conexões que articulam humanos e não humanos. Que conexões constituiram nossa pesquisa no campo da acessbilidade? Por certo, uma importante marca presente em nosso trabalho é a cegueira, já mencionada, de uma de nós. A condição de pessoa cega coloca-se como marca, como localização da pesquisa realizada,uma vez que como pessoa com deficiência, a autora ocupava dois espaços de modo muito singular: de um lado, como uma pessoa que necessita de recursos de acessibilidade, no caso em questão nesse texto, especialmente daqueles que se fazem presentes no espaço do museu. De outro lado, como um dos vetores que atuavam na promoção dessa mesma acessibilidade. Essa dupla marca - "alvo" e vetor de acessibilidade - se entrelaçam na condição de pesquisadora cega. Se, como salienta Haraway (1995), toda ótica é uma política de ver, podemos dizer que nossa ótica de pesquisa entrelaçou as políticas de 
ver e não ver e se teceu no enfrentamento e na colocação em xeque do binarismo que separa deficiência e capacidade (Mello, 2016; Dias, 2013) a1. A pesquisa, em última instância, envolveu redesenhar a própria ótica para afirmá-la como uma política cujo solo é o corpo a2, esse sim, o único solo comum - diverso, múltiplo e heterogêneo que nos reúne. É com nossos corpos que vamos aos museus. Imersos em nossos corpos, com eles, a partir deles, é que podemos usufruir e desfrutar das obras expostas. Esse é um ponto importante de nossa pesquisa.

As questões centrais que embasam esse trabalho são desdobramentos daquelas que estão em suas linhas inicias: quais são as maneiras possíveis de se ocupar o espaço do museu? O que significa propor experimentações estéticas a fim de desenvolver programas e dispositivos de acessibilidade?

Talvez, assim colocadas logo na introdução, essas questões ainda pareçam enigmáticas. Que sentidos damos à expressão "experimentação estética"? Por ora, registramos apenas que nossa proposta consistiu em retomar o sentido de experimentação proposto na arte contemporânea para embasar as ações de acessibilidade. Em consonância com os pensamentos de Oiticica a3, nos referimos ao experimental a partir de seus estudos e suas parcerias, que ao priorizarem a arte enquanto processo contínuo de estudo entre corpo, artista, espectador e obra, acreditavam que a ação artística derivava das experiências vividas. Na sequência, discutiremos a concepção de deficiência que tomamos como referência. Começaremos por esse ponto porque nos parece relevante que as versões de deficiência sejam colocadas na cena, justamente porque intepelam os sentidos e alcances das ações de acessibilidade; interpelam as pressuposições que fazemos acerca do que pode um corpo, do que são seus modos naturalizados, normais, de ver, de escutar, de andar, de falar, dentre outros. Em seguida, analisamos mais detidamente a proposição da acessibilidade estética como uma forma de acessibilidade necessária nos espaços culturais e museus, constantemente apagada frente à preponderância dos manuais técnicos a4 sobre acessibilidade. Tais manuais, extremamente necessários, não esgotam a questão da acessibilidade. Ao contrário, eles indicam as condições necessárias, mas não suficientes, para que uma acessibilidade estética seja possível.

\section{Deficiência: Modelo social e perspectiva feminista}

A perspectiva acerca da deficiência que embasa essse artigo éa do modelo social da deficiência, aí incluída a crítica feminista (Diniz, 2007; 2003). 
O modelo social da deficiência, diferentemente da perspectiva biomédica, afirma que a deficiência é o resultado da interação entre as pessoas e o seu entorno. Se na perspectiva biomédica a deficiência era tomada como uma lesão que atinge um corpo individual, no modelo social, a deficiência é afirmada com um efeito de uma sociedade pouco inclusiva, uma sociedade que oprime a diversidade dos corpos. O modelo social da deficiência se constitui a partir do movimento social das pessoas com deficiência na África do Sul (Diniz, 2007) e em outros países de língua inglesa, como o Reino Unido, especialmente na segunda metade do século XX. A reinvindicação das pessoas com deficiência era por participação nas decisões políticas que definiam os rumos de suas vidas, era também pela definição da deficiência como uma questão política, como uma luta. O modelo social é, ao fim e ao cabo, um modelo de resistência à exclusividade do discurso médico sobre a experiência da deficiência.

Ainda que o modelo social da deficiência tenha transformado o século $X X$, é importante frisar que ele não substitui o modelo médico, ou seja, não vivemos um modelo em detrimento de outro. O modelo médico da deficiência segue orientando práticas políticas à respeito da deficiência, principalmente em nosso país, no momento atual de grande retrocesso em torno das políticas sociais e de direitos humanos.

Na perspectiva do modelo social, a experiência de opressão não está inscrita no corpo da pessoa com deficiência. Ela é um efeito, uma consequência do contexto social. Ora, o modelo social da deficiência agitado pelo movimento social das pessoas com deficiência, tanto no Brasil quanto em outros países (Maior, 2017) a5 faz da deficiência uma questão de justiça social, de direitos. A gramática da deficiência não é mais a da lesão, da doença, mas sim a da justiça social e do direito. Há uma guinada no campo da deficiência na segunda metade do século XX: as pessoas com deficiência são elevadas à categoria de pessoa com direitos, coloca-se na agenda das políticas públicas (em diversas esferas) a questão da deficiência. É uma guinada extremamente relevante no campo da deficiência porque a retira do campo dos assistencialismos, da caridade, da individualização a6. A deficiência é uma questão social, coletiva, política: é uma opressão imposta por uma sociedade que exclui a variedade da paisagem corporal humana.

Outra crítica importante adveio da perspectiva feminista, que deu origem à segunda geração de teóricos do modelo social de deficiência. A revisão do modelo social da deficiência à luz do feminismo, desestabilizou a falsa suposição de que os deficientes, sem exceção, retiradas as barreiras físicas, prescidem de auxílio ou apoio de terceiros para conduzir os rumos da própria vida. O que as teóricas feministas queriam era mostrar que o cuidado também é uma demanda de justiça social dos deficientes (Diniz, 2007). Era 
preciso assimilar a ideia de que a independência não deve ser um valor central do modelo social, ou seja, as relações de dependência são inevitáveis à vida social; são inescapáveis à história de vida de todas as pessoas. A crítica feminista causou uma revolução nos estudos sobre o tema da deficiência. Como esclarece Diniz (2007), a perspectiva feminista tinha por principal desafio demonstrar a possibilidade de haver um projeto de justiça que considerasse 0 cuidado em situações de extrema desigualdade de poder, sem que isso implicasse devolver os deficientes ao espaço de subalternidade e de exclusão social.

Nisso, a crítica feminista outra vez surpreendeu, porque viabilizou o reconhecimento de outra autoridade sobre a deficiência que não apenas o deficiente, algo inquietante para a primeira geração de teóricos do modelo social, porque abalou o argumento de autoridade de que era preciso ser deficiente para escrever/falar/atuar no campo da deficiência. A figura da cuidadora foi colocada no centro do debate sobre justiça e deficiência, denunciando o viés de gênero no liberalismo político e servindo, sobretudo, como alerta para o fato de que há desigualdades de poder na área da deficiência que jamais serão resolvidas por ajustes arquitetônicos. A crítica feminista teve o papel fundamental de desvelar outros protagonistas do universo da deficiência, que vivenciam a experiência da deficiência pelo cuidado aos filhos, sobrinhos, pais, parentes e pessoas com quem não têm vínculo familiar, como é o caso de enfermeiros. Com a crítica feminista, o debate sobre a deficiência passou a considerar que a meta de uma absoluta independência é uma bandeira perversa que certamente implicará desamparo aos deficientes. Ou seja, na perspectiva feminista, o modelo social da deficiência encontra limites em função mesmo do fato de que foi um movimento proposto, majoritariamente, por homens com lesão medular, para quem o provimento de recursos de acessibilidade pode significar um imenso ganho de funcionalidade corporal. Além disso, o modelo social da deficiência, fundado num enfoque marxista, coloca como central esse ganho de funcionalidade corporal, isto é, a bandeira de luta está atrelada a uma concepção de corpo produtivo, de corpo capaz de se inserir no mercado de trabalho. Ora, mas e os corpos que não se enquadram nesse escopo? Essa é a questão levantada pelas feministas. Enquanto o modelo social da deficiência for pautado nessa perspectiva, enquanto estiver focado na luta pela promoção de corpos capazes, independentes, haverá exclusão de outros corpos deficientes para os quais os recursos de acessibilidade não promoverão, necessariamente, ganhos de funcionalidade no sentido de fazer desses corpos força de trabalho.

A crítica feminista incide diretamente sobre essa centralidade da independência como meta e reconhece que nem todos os corpos teriam a possibilidade de atingir o patamar almejado de condições 
produtivas. Sendo assim, tomam a interdependência como valor central, bem como chamam a atenção para o que significava viver num corpo lesado, recolocando em cena: a dor, a lesão e o cuidado. Realçar o papel das cuidadoras e associar a deficiência ao processo de envelhecimento também foram contribuições feministas, que estabeleceram uma conexão com variáveis de desigualdade como raça, idade e gênero, sendo a interdependência e o cuidado princípios estruturantes da vida social. Resumindo, são três pontos da argumentação feminista apresentados assim por Diniz (2003):

1) a crítica ao princípio da igualdade pela independência;

2) a emergência do corpo com lesões;

3) a discussão sobre o cuidado.

Que consequências tiramos dessa discussão para a questão da acessibilidade estética? Por certo, a interdependência é um ponto central porque diz respeito ao que nos constitui em nossa corporalidade. A interdependência é nosso destino e nossa ontologia. Algumas autoras feministas, não propriamente do campo dos estudos da deficiência, salientam que é preciso afirmar tal interdependência na radical heterogeneidade, isso é, dependemos uns dos outros, sejam humanos ou não humanos. Quanto mais múltiplas e heterogêneas são as conexões que nos constituem, mais ampliada é a nossa capacidade de agir. A questão não diz respeito, portanto, a um ideal de independência - jamais atingido, mas a uma imersão nas mais diversas e heterogêneas conexões. Pois é esse ponto que nos leva a formular uma política de acessibilidade estética, voltada não para uma fruição que envolva apenas dois termos: a obra e o espectador. Antes, o que nos interessa é uma política de acessibilidade que toma a interdependência como base, pautando-se na articulação do público com diversos elementos, incluindo-se aí as obras de arte, os corpos, as histórias, as vidas, as sensorialidades, os mais diversos atores humanos e não humanos. Porque um contato puro e real com a verdadeira obra de arte não existe, se não em relação, para pessoas com e sem deficiência.

Afirmamos que é apenas a partir das discussões sobre cuidado, interdependência e potencialidades dos corpos deficientes, que podemos pensar em uma acessibilidade estética como dispositivo de inclusão das pessoas com deficiência em Museus e Espaços Culturais.

\section{A mediação como uma ferramenta de acessibilidade estética}

É a partir da crítica que incide diretamente sobre a centralidade da independência que propomos a mediação como uma ferramenta de acessibilidade estética (Alves, 2016). Mediação é encontro, mediação é ampliação de conhecimento, mediação é ir ao encontro do repertório e dos interesses do outro, mediação é conectar conteúdos 
e interesses, mediação é ir além dos conteúdos, mediação é aproximar, refletir experiências e compartilhar, mediação é diálogo, conversação, provocação.

Mediação cultural, como propõe Miriam Celeste Martins (2014) é poder "estar entre muitos". Martins (2014) ultrapassa a ideia de mediação como ponte que une dois pontos e nos coloca para compreender esta ação - mediar - como um "estar entre muitos". Mediar é a ação de transitar, articular. É necessário cada vez mais um trabalho de mediação que ative as sensibilidades impregnadas na pele da vida. (Honorato, 2012; Martins, 2014; Kaufman, 2016; Kaufman \& Tabak, 2016). A ação de mediar, tomada como um dos dispositivos que promovem a acessibilidade estética, é, para nós, peça-chave na discussão sobre acessibilidade em museus e espaços culturais. Se retomamos as perguntas que abriram esse texto, afirmamos que, como educadores e agentes promotores da acessibilidade em espaços culturais e museus, o que nos cabe é propor mediações que articulem as obras expostas e os espectadores, quem quer que sejam esses espectadores, com seus corpos e suas marcas. Tais mediações não tem como finalidade revelar a verdade última da obra. São antes experimentações possíveis a partir das obras, são mobilizaçõesdos corpos dos espectadores não pelo que Ihes falta, mas pelo que Ihes constitui. Uma obra eminentemente visual estará, enquanto forma visual, inalcansável para uma pessoa cega. Essa afirmação, porém, não esgota a questão do acesso desssa obra por uma pessoa cega. Ao contrário, abre outras questões: que mediações podem promover articulações entre a obra e o corpo que não vê? Com quantas mediações se promove uma acessibilidade estética? Kaufman (2016) discorre sobre a mediação no campo da inclusão escolar e, a despeito das diferenças entre os campos de nossos trabalhos, encontramos ressonâncias com as propostas da autora. Nas suas palavras "[...] não podemos decidir o que será mediador para o aluno em situação de inclusão [...] [a pista é] oferecer diferentes possibilidades, correr riscos, acreditando que 0 aluno será capaz de decidir o que daquilo que lhe é oferecido vem em seu auxilio, e se torna seu mediador [...]. (Kaufman, 2016, p. 91). Trata-se, sem dúvida, de uma concepção de mediação que vem ao encontro de nossa proposta e que coloca o acento em pelo menos três pontos que nos são caros. Em primeiro lugar, mediar é oferecer diferentes possibilidades, correndo o risco de não saber de antemão o que produzirá efeitos, nem mesmo que efeitos se produzirão no encontro com o outro. Em segundo lugar, a mediar envolve tomar o outro como expert, como parceiro no processo de fazer uma obra acessível. E por fim, mediar envolve experimentar.

Nesse ponto, é preciso recorrrermos ao legado que a arte contemporânea nos deixou, retomando o sentido de experimentação que aparece especialmente no trabalho de Hélio Oiticica. 
O experimentalismo surgiu em meio às propostas neoconcretas, que procuravam explorar na arte um novo ambiente expressivo, fenomenológico - inspiradas em Merleau Ponty - e perceptivo, relativizando os espaços e limites entre linha e quadro. Ao priorizar a arte enquanto processo contínuo de estudo entre corpo, artista, expectador e obra, esses artistas acreditavam que a ação artística derivava das experiências vividas. [...] Neste sentido, o termo experimental serviu para designar a busca de liberdade em utilizar variados materiais de maneiras múltiplas como artifício artístico, a partir de novas mídias e novas propostas, como 'caminho sensorial', em que o corpo é entendido como força motriz. O resultado final, que seria a obra, foi considerado parte da vivência do espectador e do artista, enquanto maneiras de diálogo, desviando assim o caráter da arte como meramente visual para o domínio experimental. (Silva, 2010, p. 2).

Nestes termos, ao longo das produções de artistas como Hélio Oiticica, o experimental serviu para designar a busca de liberdade em utilizar variados materiais, de maneiras múltiplas, como artifício artístico, a partir de novas mídias e novas propostas, como "caminho sensorial" em que o corpo é entendido como força motriz. O resultado do experimental é que ele é livre, pois não se repete.

Nesse trabalho, tomamos o conceito de experimental como sendo a ação que traz novos valores, novas leituras para o campo da acessibilidade. Assumir o experimental em um trabalho de acessibilidade é assumir que uma obra de arte não tem sentido em si, ou que a curadoria de uma exposição não garante a leitura da exposição por parte do visitante, mas é garantir que existe e persiste neste processo experimental uma positividade, algo esperando para emergir. Podemos dizer que a acessibilidade estética, do modo como a entendemos, é sempre e necessariamente, experimental. É no encontro com o outro, com suas marcas, com suas singularidades, que alguma possível fruição de uma obra irá emergir. O que afirmamos, portanto, é que a acessibilidade estética diz respeito a uma possibilidade de fruição de uma obra de arte que se faz de forma encarnada, vivida, experimental e experimentada. Que um dos dispositivos para se levar adiante essa proposta de acessibilidade é a mediação cultural, tomada não como um estoque de informações a serem dadas aos espectadores, nem como uma ponte que liga a obra ao espectador, mas antes como uma ação de estar entre muitos, como uma ação de afetar e ser afetado que mobiliza os mais diversos e heterogêneos elementos a fim de promover o acesso a uma obra, pela via estética e experimental. 
Se, como dizemos, o campo da acessibilidade na arte é cheio de fios soltos, o que gera um campo de possibilidade que podemos explorar, temos para nós que uma das direções deixadas por estes fios, é a dimensão de fazer um trabalho de acessibilidade compartilhado, um modo de fazer trabalho e produzir conhecimento que denominamos pesquisarCOM (Moraes, 2010).

O pesquisarCOM (Moraes, 2010) se contrapõe neste momento há uma outra metodologia no campo da acessibilidade que vem se tornando cada vez mais comum: os manuais. Os manuais são orientados para uma intervenção que se orienta num fazer PARA os outros, que é uma orientação importante no campo da acessibilidade, porém insuficiente para dar conta de muitas de suas dimensões. Tomamos aqui esses manuais que estão sendo sistematicamente criados e distribuídos, como uma metodologia de trabalho na medida que os usos que se fazem deles, criam uma realidade no dia a dia do trabalho com as pessoas com deficiência.

Neste texto fazemos a você leitor um convite, um convite paraque pensemos para além dos manuais de acessibilidade uma vez que, como dito, eles são necessários, mas, insuficientes, porque dizem respeito a adaptações arquitetônicas e informacionais sem questionarem as maneiras como vêm sendo propostas, quando são propostas, as experimentações mais estéticas e expressivas de uma exposição ou deuma determinada obra.

Basta uma informação para garantir o acesso de uma pessoa a uma obra de arte? A informação é tomada como um elemento predominante de conhecer. Ter acesso à informação de uma obra esgota a questão de fruição (experimentação) de um visitante? Conversando com Bondia (2002), podemos afirmar que:

A informação não é experiência. E mais, a informação não deixa lugar para a experiência, ela é quase o contrário da experiência, quase uma antiexperiência. Por isso a ênfase contemporânea na informação, em estar informados, e toda a retórica destinada a constituir-nos como sujeitos informantes e informados; a informação não faz outra coisa que cancelar nossas possibilidades de experiencia. (Bondia, 2002, p. 21-22).

É preciso separar a experiência da informação. (Bondia, 2002). A acessibilidade estética separa a experiência da informação (Alves, 2016; Carijó, Magalhães \& Almeida, 2012; Kastrup, 2010). Os manuais, em geral, têm servido como um dispositivo de informação como garantia de uma trajetória incerta, de uma trajetória que é feita no encontro COM o outro e não SOBRE ou PARA o outro somente.

Fato é que os manuais não tratam de histórias, os guias não tratam de histórias, eles tratam do que está pronto e histórias não estão prontas. Histórias estão sempre por vir, histórias só se dão no 
encontro (Franco, 2016; Manso, 2016). Os manuais se dão para antecipar o encontro, surgem na tentativa de garantir o sucesso de um encontro, por isso eles não lidam com histórias, não com histórias em movimento. Os guias e manuais estão sempre diante de histórias cristalizadas, naturalizadas, histórias únicas (Alves, 2016).

A nossa proposta é que a acessibilidade seja também um dispositivo de memória, um testemunho, uma contação de história. Nos interessa pensar o papel do mediador, e do pesquisador, como aquele que leva adiante a palavra do outro e que, para isso, há de suportar o que o afeta no encontro com o outro.

Trabalhar com acessibilidade está para além da lida com normas técnicas, medidas arquitetônicas, padrões de informação. Isso não significa que estas questões não façam parte deste trabalho. Fazem e são necessárias, porém, não podemos tomá-las como as únicas discussões dentro desta área. A mediação envolve vidas. Trabalhamos com minorias atravessadas pelo sofrimento. Seja o sofrimento da perda de algum sentido, da experiência de uma marginalidade social, seja o sofrimento por comporem o que chamamos de minorias, de experiências minoritárias a7.

Trabalhar com a deficiência em um centro cultural é também poder levar histórias adiante, é acompanhar essas experiências se fazendo no dia a dia, em cada visita, é poder criar memórias com as pessoas com quem trabalhamos, em nós e no espaço que trabalhamos. Como diria Haraway,

a memória quente e incorporada, uma memória que destaca hábitos e intimidades, uma memória que traduz um processo de 'tornar-se com' aquilo a que nos dirigimos, o que nos coloca a trabalhar, o que nos metamorfoseia e através do que se aprende as linguagens do mundo, do espaço e do tempo. Uma memória de modos de ser, de ritmos, de estilos, de propagação, de combinações [...] Uma memória que impõe e que resume um gesto particular: aquele de 'compor com'. (Haraway, 1995, p. 4).

Como então fazer um trabalho de mediação em acessibilidade em que cada um seja ativo diante de sua própria experiência? Recorremos à memória de um dos nossos encontros de mediação, realizado no ano de 2013.

Acontecia a terceira semana de Conscientização Mundial do Autismo. Como de costume, tínhamos agendado a visita de muitos grupos vinculados às instituições que trabalham com pessoas autistas a8. Em cartaz uma exposição de pintura do artista mineiro Carlos Bracher. A preocupação para o acolhimento dos grupos era a mesma dos anos anteriores. As outras edições do evento nos deram experiência, mas não um território estável, pelo contrário, 
entendemos ao longo dos anos de realização deste projeto que a experiência do autismo é tão plural que desestabiliza qualquer território que ouse se estabilizar, e isso é uma das maiores heranças que esse trabalho nos deixou. Era uma preocupação naquele momento o que poderíamos propor para estes grupos, diante de uma exposição absolutamente clássica, com relação à sua montagem (quadros na parede). Os manuais dizem que autistas tem dificuldades de fazer contato visual, restringi-los a um contato visual diante dos quadros, que por vezes produz uma deficiência em seus corpos não seria uma saída interessante. Fazê-los parar diante de uma necessidade corporal de entrar em movimento não respeitaria as especificidades desses grupos. O que poderíamos fazer então? Bom, para a ocasião criamos uma maleta de possibilidades. Entendemos que restringir o público a uma única experiência poderia fazer com que nenhuma experiência fosse possível. A maleta tinha sua parte externa pintada com as cores, texturas e pinceladas do artista em questão na exposição. Do lado de dentro, muitas flores artificiais que faziam referência às pinturas de tema "Natureza Morta". Um som portátil que tinha uma playlist que criava paisagens sonoras relacionadas com as obras, por exemplo: um som de sino de igreja e pinturas de igreja. Muitos tecidos com os tons das cores utilizadas pelo Bracher, pincéis e tubos de tinta, espelhos que faziam relação com o "Autorretrato", tema também presente nesta exposição. A maleta foi a criação de condições de possibilidades para uma experiência estética. Nesse momento, os educadores tinham apenas uma maleta nas mãos para seguir com a visita. O que aconteceria na galeria era da ordem do imprevisível, no sentido de não planejado.

Começamos a visita apresentando a maleta. Todos quiseram tocála... A textura era realmente atraente. Percebemos que o objeto mediador despertava interesse. Fomos para a galeria com tudo aquilo, sem saber exatamente como iríamos usar tantos elementos, porém, essa dúvida foi extinta já na primeira sala, onde os próprios participantes foram nos levando, dando direção e sentido para a mediação. Com os tecidos coloridos eles se enrolaram, quando perguntávamos sobre um ou outro, por exemplo: Cadê o Gabriel? Cadê a Laurinha? Os mesmos apontavam para os quadros na direção das cores que os cobria. Naquele momento Laurinha era o verde, Gabriel o vermelho. Uma mediadora cega, que assina esse texto, seguiu nessa visita acompanhada de muitas cores! O movimento de se tornar cores não fazia parte do nosso roteiro. Nem por isso interrompemos esse movimento. Permitir que o outro seja ativo diante da sua própria experiência, mudar os rumos do planejamento e tomar o outro como um sujeito de conhecimento de sua própria experiência, esse é também um desafio para a mediação em acessibilidade. Há nesse exercício um desafio de ocupar um lugar não de um suposto saber, mas há aí uma torção que aparece neste relato 
que questiona o nosso próprio preparo, e com ele se abre não para oferecer uma experiência para o outro, mas para também receber o que vem com o outro. Se abrir para o que estar por vir, a isso chamamos de dissenso. O dissenso é próprio do dispositivo, da construção de algo que está em movimento, em transformação constante. Para tomar a mediação como um dispositivo é preciso estar no dissenso, e para estar no dissenso é preciso ser mediado. Mas porque isso não pode ser programado, a mediação pode ser então o que se põe à espreita do dissenso.

Pensar em uma ética de acessibilidade seria pensar em um programa COM ações que levassem em conta as vidas, as histórias e as memórias das pessoas COM quem trabalhamos. Um programa que se interessasse mais pelas histórias do que pelas deficiências, mais pelo que cada um tem do que pelo que Ihes falta, uma acessibilidade que fosse ela produtora de novas e diferentes histórias, mais do que reprodutora das histórias de sempre. O que cada encontro faz falar e o que cada encontro faz calar? O que cada visita fazaparecer e desaparecer? Entendemos as visitas mediadas como um dispositivo de fazer falar, de trazer o outro para a roda, de partilhar COM aqueles que recebemos nos espaços culturais e museus as experiências que o encontro com as obras ativa em cada um, de forma singular.

PesquisarCOM é um ato de começar por dentro, de começar investigando quem está dentro da história. Começar por dentro é um ato de afirmação do outro, de confiança nasuatrajetória. A proposta de fazerCOM o outro a acessilidade, de apostar no encontro, na mediação como dispositivo, é também uma retomada do lema do movimento social da deficiência, "nada sobre nós sem nós". A proposta que fazemos é, portanto, que a acessibilidade estética é uma experiência de partilha que investe no encontro, no fazerCOM e não sobre ou para as pessoas.

A acessibilidade não é, então, concebida como um conjunto de ações que teriam como meta proporcionar o alcance a um conhecimento ou informação a priori, mas como criação de condições para a produção de múltiplos sentidos na experiência com a arte. Eis uma questão que se revela como zona de risco e como instigadora para a mudança de valores e de parâmetros da mediação ou da acessibilidade.

Dessa maneira, propomos um outro tipo de atenção ao pensamento, uma atenção que ao invés de se doar para uma recognição, para um reconhecimento de algo já dado (Kastrup, 2010) se forme à espreita, numa atenção que crie em nós uma abertura para os encontros, os estranhamentos e os solavancos que estão por vir. Isso porque, como dito, a experiência estética de uma obra de arte é algo que não se reduz à aquisição de informação.

Assim, numa política diferente, pode-se tomar como objetivo a promoção de experiências estéticas por meio do contato direto com 
as obras. Tal orientação preocupa-se menos com o conhecimento formal que o público vai adquirir sobre as obras, movimentos e artistas, e mais com o afeto estéticoque a experiência com as obras pode despertar (Kastrup \&Vergara, 2013).

Uma boa proposta de acessibilidade é, então, aquela que não se ocupa somente dos direitos das pessoas com deficiência no que concerne ao acesso à informação e aos espaços, mas que vai além, buscando assumir um compromisso estético (Kastrup, 2010).

Outra questão de grande importância que também nos interessa, é o aspecto político destes trabalhos. Por séculos a deficiência vem sendo constituída no Ocidente como sinônimo de déficit e de incapacidade. Tal concepção de deficiência como déficit incorporou-se nas práticas sociais, o que inclui a vivência dos espaços de arte.

Essa concepção da experiência da deficiência como déficit nos conduz a um tipo de prática de intervenção no campo da deficiência visual, por exemplo, que instaura uma assimetria entre a deficiência e capacidade. Isto é, muitas das vezes se intervém para restaurar as perdas que marcam a cegueira, o que coloca as pessoas que veem numa posição superior, de saber sobre aquele que não vê.

Uma intervenção assim ordenada acaba por produzir uma distribuição assimétrica de capacidade e deficiência, isto é, aquele que intervém o faz em nome da capacidade a ser alcançada e aquele que é "alvo" da intervenção aparece como alguém a quem falta uma certa capacidade. Abrir a possibilidade para um programa de acessibilidade que produza uma intervenção simétrica também é um objetivo deste trabalho. Acrescentamos que a aposta no experimental como um conceito indicador para um trabalho de acessibilidade abre um espaço cheio de possibilidade para que nós, pessoas com e sem deficiência, possamos nos afetar e contar mais e novas histórias a respeito das nossas experiências.

\section{Considerações finais}

E o que toda essa discussão tem a ver com um programa de acessibilidade em museus e centros culturais?

Somos responsáveis pelas escolhas metodológicas que fazemos para o trabalho que realizamos. Como pensar em uma metodologia que possibilite o surgimento de novas e outras histórias a respeito das vidas das pessoas com deficiência e desse modo fazer proliferar outras versões para além de um romantismo que por vezes toma e é tomado pelas pessoas que vivenciam a experiência da deficiência e por outro lado, uma visão fatalista, que funda uma tragédia pessoal na qual as vidas das pessoas com deficiência são desenhadas?

Pensar em uma metodologia de trabalho implica se comprometer com os efeitos que ela irá produzir. Com tal questão em mente, 
perguntamos: Que efeitos e histórias podem produzir um programa de acessibilidade pautado no uso de manuais e dispositivos que se dedicam basicamente à informação e que efeitos e histórias podem produzir um programa de acessibilidade pautado na direção do experimental?

Nos parece que um programa que se baseie apenas em manuais e dispositivos de informação corre o risco de instaurar uma assimetria entre a deficiência e a capacidade. Isto é, muitas das vezes se intervém para restaurar as perdas que marcam a deficiência, o que coloca as pessoas sem deficiência numa posição superior, de saber sobre aquele com deficiência.

Seguir os modos de ordenar a deficiência, acompanhar as versões de deficiência feitas cotidianamente, trilhar pelas bifurcações, pelas variações, eis alguns dos pontos que embasam o pesquisar com 0 outro e não sobre/para o outro (Moraes, 2010).

Interpelar o outro, no caso, o outro com deficiência, não como um sujeito dócil, como um sujeito qualquer, mas antes, como dissemos, como um expert, como alguém que pode conosco formular as questões que são interessantes para um programa de acessibilidade. O nada sobre nós sem nós, pauta dos movimentos sociais da deficiência, implica tomar a pessoa com deficiência não apenas como um alvo da acessibilidade, mas como um expert, como alguém que é co-participante no processo de experimentar a obra.

Antes de qualquer coisa, uma proposição não técnica para a acessibilidade pressupõe um acolhimento, levar em consideração o outro, entender que o acolhimento é uma maneira de propor, de provocar uma experiência, de estar entre muitos e, portanto, estar em relação com quem chega.

Reafirmamos aqui uma proposição não técnica que, ao invés de oferecer regras a seremseguidas, ofereça histórias. Que propõe um experimentar e não um definir experiências organizadas em tópicos.

Em uma proposição não técnica apostamos, coletivamente, no ato de contar histórias para também aprendermos sobre o que não sabemos, para compartilhar o que aprendemos nesses encontros, para levar adiante a história do outro, porque acreditamos nessa possibilidade, de tornar o mundo mais denso de histórias e experiências que importam.

Histórias são frutos de um encontro, são tecidas coletivamente, mas na proposição que fazemos, indicamos também que colhendo e contando histórias podemos nos ajudar e nos preparar para esses encontros. Como salientam Prestrelo (2017) e Mol (2008), as histórias a serem narradas e partilhadas a partir da mediação, são sempre locais, singulares. Não há como generalizar um procedimento "imutável" de um lugar para outro. É preciso, porém, tomar essas histórias como trajetórias sensíveis que possam se conectar a outros contextos, a outros cenários. Não como uma totalidade fechada, mas 
como faíscas, fagulhas que interroguem outras pessoas, outros corpos mobilizados pela questão da acessibilidade, em especial da acessibilidade estética. Se, a partir desse texto, uma fagulha sensível puder conectar-se em outro cenário para articular ações de acessibilidades estéticas, singulares, situadas, então alguma coisa terá se deslocado da nossa experiência no campo da acessibilidade.

Ressaltamos aqui, mais uma vez, que este trabalho em nenhum momento é contra os manuais, mas sim que esses manuais, da maneira como são feitos, dessa forma técnica, precisa e rigorosa, não dão conta da experiência da acessibilidade.

Se defendemos que possamos elaborar proposições não técnicas de acessibililidade é para apostarmos que a acessibilide é, e sempre será, experimental. Porque não há manual, entendido como uma definição prévia de como alguma coisa funciona, capaz de dar conta da diversidade da paisagem corporal humana. Nossas proposições não técnicasretomam (Alves, 2016) o sentido de manual que envolve as mãos, envolve artesania: um fazer situado que se dá no encontro. Por certo, a mediação cultural diz respeito a planejamentos, a discussões sobre o como fazer. Mas é certo também que é no encontro com as pessoas com deficiência que a acessibilidade estética se dará: é com as pessoas, com suas vidas e histórias, com seus corpos e experiências que a experiência da acessbilidade ocorrerá.

Mais do que responder a alguma questão prévia, as narrativas de uma proposição não técnica de acessibilidade precisam nos colocar questões. Colocar questões também deve ser mais uma direção de trabalho.

Uma proposição não técnica no campo da acessibilidade em espaços culturais e museus leva em conta que se há uma coisa que todos nós, sem exceção, temos, é um corpo. Tomar esse corpo com suas marcas, com suas histórias, com suas possibilidades e sensorialidades como ponto de partida da mediação é um pilar importante, é uma prática de cuidado a9 e de acolhimento.

Arriscamos aqui a dizer a essa altura que uma experimentação estética parte então dos seguintes pilares:

- Ela é coletiva;

- Investe nos laços, nas conexões;

- Parte do corpo com suas marcas e histórias, com seus mundos possíveis;

- É uma prática de cuidado e acolhimento;

- Reconhece o outro como expert.

Por fim, nos parece importante dizer que nem um manual técnico, nem uma proposição não técnica são garantias de um caminho seguro, um caminho dado, possível de organizar um método permanente de fazer um programa de acessibilidade, mas ao contrário, cada nova visita, cada nova situação, coloca um novo 
problema. Uma proposição não técnica exige de nós que sejamos capazes de suportar uma não garantia.

Próximo da prática de um malabarista na corda bamba que não se deixaria amarrar para prevenir uma queda: se assim o fizesse, ele estaria seguro quanto ao seu destino, mas não pareceria um homem muito habilidoso, o mediador deveria diante dessa proposta ser um mediador malabarista, capaz de criar um corpo que suporte 0 desequilíbrio, a instabilidade.

Por último, ler este texto esperando instruções estáveis para com ele aprender a fazer um bom trabalho de acessibilidade é contrário ao seu próprio objetivo. Nossa aposta é que a leitura desse trabalho tenha se dadonum modo de conhecer próprio da cegueira isto é, tateando. Que esse texto seja também mais uma ferramenta tátil para que seja possível criar cada vez mais um trabalho que se ocupe de uma produção mais estética no campo da acessibilidade em espaços culturais e museus.

\section{Referências}

Alves, C. A. (2016). E se experimentássemos mais? Um manual não técnico de acessibilidade em espaços culturais (Dissertação de mestrado não publicada). Programa de Pós-graduação em Psicologia, Universidade Federal Fluminense, Niterói, RJ.

Alves, C. A., \& Moraes, M. (2018). Entre Histórias e Mediações: Um caminho para acessibilidade estética em espaços culturais. Psicologia: Ciência e Profissão, 38(3), 584-594. doi:10.1590/1982-3703000042018

Bondía, J. L. (2002). Notas sobre a experiência e o saber de experiência. Revista Brasileira de Educação, (19), 21-28. doi:10.1590/S1413-24782002000100003

Carijó, F. H., Magalhães, J. Q., \& Almeida, M. C. (2012). Acesso tátil: Uma introdução a questão da acessibilidade estética para o público deficiente visual nos museus. Sobre a deficiência visual. Recuperado de http://www.deficienciavisual.pt/txtAcesso_tactil_DV_museus.htm

Dias, A. (2013, Junho). Por uma genealogia do capacitismo: Da eugenia estatal a narrativa capacitista social. Anais do Simpósio Internacional de Estudos sobre a Deficiência SEDPCD/Diversitas/USP Legal, São Paulo, SP, Brasil, 1. Recuperado de http://www.memorialdainclusao.sp.gov.br/ebook/Textos/Adrian a_Dias.pdf

Diniz, D. (2007). O que é deficiência? São Paulo: Brasiliense. 
Diniz, D. (2003). Modelo social da deficiência: A crítica feminista. Série Anis 2B, 28, 1-10. Recuperado de http://repositorio.unb.br/handle/10482/15250

Franco, L. O. P. (2016). Por uma política da narratividade: pensando a escrita no trabalho de pesquisa. Niterói: Eduff.

Haraway, D. (1995). Saberes localizados: A questão da ciência para o feminismo e o privilégio da perspectiva parcial. Cadernos Pagu, (5), 7-41. Recuperado de https://periodicos.sbu.unicamp.br/ojs/index.php/cadpagu/articl e/view/1773

Haraway, D. (2008). When speeces meet. Minneapolis: University of Minnesota Press.

Honorato, C. (2012, Setembro). Usos, sentidos e incidências da mediação: Questões de Vocabulário. Anais do Encontro da Associação Nacional de Pesquisadores em Artes Plásticas, Rio de Janeiro, RJ, Brasil, $21 . \quad$ Recuperado de http://www.anpap.org.br/anais/2012/pdf/simposio5/cayo_hono rato.pdf

Kastrup, V. (2010). Experiência estética para uma aprendizagem inventiva: Notas sobre o acesso de pessoas cegas a museus. Informática na Educação: Teoria \& Prática, 13(2), 38-45. doi:10.22456/1982-1654.12463

Kastrup, V., \& Vergara, G. (2013). Zona de risco dos encontros multisensoriais: Anotações éticas e estéticas sobre acessibilidades e mediações. Revista Trama Interdisciplinar, $4(1), 53-68$.

Kaufman, N. (2016). Mediação Escolar: Tecendo Pistas Entre Muitos (Dissertação de Mestrado). Programa de Pós-graduação em Psicologia, Universidade Federal Fluminense, Niterói, RJ.

Kaufman, N., \& Tabak, S. (2016). Inclusão e mediação escolar: Norteadores para uma prática ética. Educação Online, (22), 2742. Recuperado de http://educacaoonline.edu.pucrio.br/index.php/eduonline/article/view/263

Maior, M. I. M. L. (2017). Movimento político das pessoas com deficiência: Reflexões sobre a conquista de direitos. Inclusão Social, 10(2), 28-36. Recuperado de http://revista.ibict.br/inclusao/article/view/4029/3365

Manso, C. C. (2016). Narrativas do não ver: (re)criações do corpo e do cegar. Niterói: Eduff.

Manso, C. C. (2015). O fazer-cuidar: Seguindo práticas de cuidar nas Equipes de Saúde da Família e nos Núcleos de Apoio à Saúde da Família (Tese de Doutorado). Programa de Pós-graduação em Psicologia, Universidade Federal Fluminense, Niterói, RJ.

Martins, M. C. (2014). Mediações culturais e contaminações estéticas. Revista Gearte - UFRGS, 1(3), 248-264. doi:10.22456/23579854.52575 
Mello, A. G. (2016). Deficiência, incapacidade e vulnerabilidade: Do capacitismo ou a preeminência capacitista e biomédica do Comitê de Ética em Pesquisa da UFSC. Ciência \& Saúde Coletiva, 21(10), 3265-3276. doi:10.1590/1413812320152110.07792016

Mol, A. (2008). The logic of care. Health and the problem if patient choice. London: Routledge.

Moraes, M. (2010). PesquisarCOM: política ontológica e deficiência visual. In M. Moraes, \& V. Kastrup (Orgs.), Exercícios de ver e não ver: Arte e pesquisa com pessoas com deficiência visual (pp. 26-51). Rio de Janeiro: Nau Editora.

Ortega, F. (2009). Deficiência, autismo e neurodiversidade. Ciência e saúde coletiva, 14(1), 67-77. doi:10.1590/S141381232009000100012

Prestrelo, E. T. (2017). Histórias que (nos) contam: O encantamento dos dias de uma "vida vivida" (Tese de Doutorado). Programa de Pós-graduação em Psicologia, Universidade Federal Fluminense, Niterói, RJ.

Silva, A. C. G. (2010, Julho). Experimentar a arte, experimentar a si: Helio Oiticica, entre memórias. Anais do Encontro Nacional da Anpuh Rio de Janeiro, UNIRIO, Rio de Janeiro, RJ, Brasil, 14.

\section{Endereço para correspondência \\ Camila Araújo Alves}

Universidade Federal Fluminense

Campus Gragoatá, bloco N, $4^{\circ}$ andar, sala 417, CEP 24210-201, Niterói - RJ, Brasil

Endereço eletrônico: camilaaraujoalves@yahoo.com.br

\section{Marcia Moraes}

Universidade Federal Fluminense

Campus Gragoatá, bloco N, $4^{\circ}$ andar, sala 417, CEP 24210-201, Niterói - RJ, Brasil

Endereço eletrônico: marciamoraes@id.uff.br

Recebido em: 15/04/2019

Aceito em: 28/06/2019

\section{Notas}

* Psicóloga Clínica pela Universidade Federal Fluminense (UFF). Mestre em Psicologia pela UFF. Doutoranda do Programa de Pós-graduação em Psicologia da UFF. Psicoterapeuta Corporal e Docente do curso de Psicologia das Universidades Integradas Maria Thereza.

** Professora Titular do Departamento de Psicologia da Universidade Federal Fluminense (UFF). Docente permanente do Programa de Pós-graduação em Psicologia da UFF. Doutora em Psicologia pela Pontifícia Universidade Católica de São Paulo (PUC/SP).

1 Anahi Guedes de Mello (2016) afirma que o binarismo que opõe deficiência e capacidade é histórica e socialmente construído. A autora salienta que o capacitismo é o preconceito que segrega e subalterniza certos corpos com base em uma suposta capacidade funcional ideal a ser alcançada por todos os corpos. Dias 
(2013) apresenta interessante discussão sobre a genealogia do capacitismo no cenário social contemporâneo.

${ }^{2}$ Nesse texto seguimos a definição de corpo proposta por Haraway (2008): "[...]o corpo é sempre um fazer; é sempre um emaranhado vital de escalas, tempos, maneiras de ser heterogêneas ligadas em presença encarnada, sempre um tornarse, sempre constituído em relação [...]. Porque nós nunca fomos o humano da filosofia, nós somos corpos em tramas." (Haraway, 2008, p. 163-165).

${ }^{3}$ Hélio Oiticica foi um artista plástico brasileiro, pintor, escultor e destacado artista performático. Foi um dos grandes nomes da arte concreta no Brasil. No fim dos anos 50 entra para o coletivo de artistas do Grupo Neoconcreto, que passa a entender que o público é parte da obra de arte, podendo e devendo tocá-la, sentí-la e até mesmo experimentá-la (Alves, 2016).

4 No curso desse texto, quando nos referirmos aos manuais técnicos de acessibilidade, não faremos referência a nenhum manual específico, organizado por uma instituição específica. Ao fazer referência a tais manuais, colocamos em questão um modo de organizar o pensamento e as intervenções no campo da acessibilidade.

5 Recomendamos aos leitores além do precioso texto de Izabel Maior, o vídeo História do Movimento Social das Pessoas com Deficiência no Brasil. Recuperado a partir de https://www.youtube.com/watch?v=oxscYK9Xr4M.

${ }^{6}$ Maior (2017) nos permite afirmar que no Brasil, a constituição federal de 1988 foi fundamental para afirmar a deficiência como uma questão de justiça social, de direitos humanos, transversalizada nas diferentes políticas públicas.

7 Neste caso, a minoria não representa apenas a expressão numérica daqueles grupos que não se enquadram no padrão estabelecido pelo senso comum da maioria, mas, intensivamente minorias são a respiração vital da maioria, ou seja, elas formam um "devir minoritário". Chamamos de experiências minoritárias, as experiências que fazem valer as transformações, de uns nos outros e as transformações de si mesmos e transformações inclusive dos museus e centros culturais (Alves, 2016).

8 Nesse texto tomamos o autismo como deficiência, no sentido proposto pelo modelo social da deficiência. Reconhecemos as controvérsias que marcam esse campo, porém para os efeitos de nossos argumentos nos interessa reconhecer que pessoas autistas são, não raras vezes, oprimidas por ambientes e cenários sociais pouco inclusivos. Para seguir no debate desse tema, sugerimos Ortega (2009).

${ }^{9}$ Utilizamos a noção de prática de cuidado no sentido proposto por Prestrelo (2017) e por Manso (2015), isto é, como prática distribuída que articula elementos humanos e não humanos. O cuidado, na perspectiva das autoras, é uma prática que exige ajuste contínuo, uma sintonia fina no sentido de articular os mais diversos e heterogêneos elementos. Não é uma prática dual, que se organiza em dois polos apenas: um que oferta o cuidado, outro que recebe o cuidado. É antes uma prática em rede, que depende do engajamento daqueles que nela se articulam, sejam humanos ou não humanos.

Financiamento: Capes, CNPq e Faperj.

Este artigo de revista Estudos e Pesquisas em Psicologia é licenciado sob uma Licença Creative Commons Atribuição-Não Comercial 3.0 Não Adaptada. 